\title{
Recent Advances in Substrate-Controlled Asymmetric Induction Derived from Chiral Pool $\alpha$-Amino Acids for Natural Product Synthesis
}

\author{
Seung-Mann Paek ${ }^{1}$, Myeonggyo Jeong ${ }^{2}$, Jeyun Jo ${ }^{2}$, Yu Mi Heo ${ }^{1}$, Young Taek Han ${ }^{3}$ and \\ Hwayoung Yun ${ }^{2, *}$ \\ 1 College of Pharmacy, Research Institute of Pharmaceutical Science, Gyeongsang National University, \\ Jinju daero, Jinju 52828, Korea; million@gnu.ac.kr (S.-M.P.); yumiizzi11@naver.com (Y.M.H.) \\ 2 College of Pharmacy, Pusan National University, Busan 46241, Korea; navy7750@gmail.com (M.J.); \\ jju02160@gmail.com (J.J.) \\ 3 College of Pharmacy, Dankook University, Cheonan 31116, Korea; hanyt@dankook.ac.kr \\ * Correspondence: hyun@pusan.ac.kr; Tel.: +82-51-510-2810; Fax: +82-51-513-6754
}

Academic Editors: Carlo Siciliano and Constantinos M. Athanassopoulos

Received: 15 June 2016; Accepted: 18 July 2016; Published: 21 July 2016

\begin{abstract}
Chiral pool $\alpha$-amino acids have been used as powerful tools for the total synthesis of structurally diverse natural products. Some common naturally occurring $\alpha$-amino acids are readily available in both enantiomerically pure forms. The applications of the chiral pool in asymmetric synthesis can be categorized prudently as chiral sources, devices, and inducers. This review specifically examines recent advances in substrate-controlled asymmetric reactions induced by the chirality of $\alpha$-amino acid templates in natural product synthesis research and related areas.
\end{abstract}

Keywords: chiral pool; $\alpha$-amino acid; natural product; total synthesis; asymmetric induction

\section{Introduction}

The chiral pool approach is highly attractive in the asymmetric total synthesis of bioactive natural products with diverse and complex architectures [1,2]. This strategy is one of the best methods available to synthetic organic chemists for establishing pivotal stereocenters in optically active compounds [3-7]. The chiral pool is a versatile tool, comprising naturally occurring chiral molecules such as carbohydrates, amino acids, terpenes, alkaloids, and hydroxyacids [2,6]. They include enantiomerically enriched species that can be synthetically transformed into the desired target molecules. Chiral pool materials are also inexpensive and commercially available, making them adequate for use in accessing natural products and bioactive compounds [2]. The usage of the chiral pool in asymmetric synthesis can be classified in three general categories, as shown in Figure 1: (a) chiral sources, used as building blocks containing built-in stereocenters for target molecules; (b) chiral devices, employed as useful tools for enantioselective catalysts and auxiliaries; and (c) chiral inducers, applied to the generation of new stereocenters in a substrate-controlled manner [1-7]. The chiral inducer strategy is a highly efficient method to exploit advantages of both the chiral source and device approach at the same time.

The specific aim of this review is to present useful applications of enantiomerically enriched $\alpha$-amino acids as substrate-controlled asymmetric inducers in natural product synthesis from 2011 to May 2016. Chirally pure $\alpha$-amino acids are very useful materials due to diversity of functional group and ease of commercial use [7]. The $\alpha$-amino acids described in this review are illustrated in Figure 2. The use of amino acids as chiral sources and devices for asymmetric synthesis is not covered. Also, synthesis of acyclic or cyclic peptide natural products is not included. 
(a) chiral sources

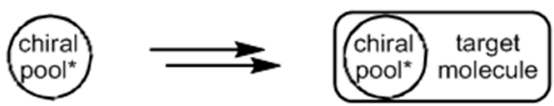

(b) chiral devices

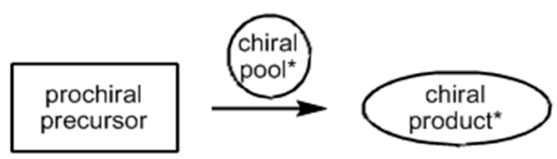

(c) chiral inducers

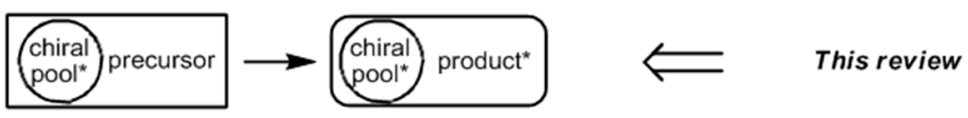

Figure 1. Three categories of chiral pool use in asymmetric synthesis.

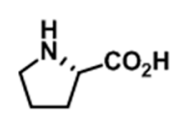

Proline<smiles>NC(=O)Cc1c[nH]c2ccccc12</smiles>

Tryptophan<smiles>NC(=O)Cc1ccc(O)cc1</smiles>

Tyrosine<smiles>N[C@@H](CO)C(=O)O</smiles>

Serine<smiles>CC(N)C(=O)O</smiles>

Alanine<smiles>C[C@H](O)C(N)C(=O)O</smiles>

Threonine

Figure 2. Representative $\alpha$-amino acids.

\section{Chiral Pool: Proline}

Recently, a wide range of natural and non-natural product syntheses using proline as the chiral pool material in a substrate-controlled manner have been reported. Suh et al. synthesized polyhydroxylated indolizidine alkaloids, 1-deoxy-6,8a-di-epi-castanospermine (4) and 1-deoxy-6-epi-castanospermine (7), that can act as selective $\alpha$-glycosidase inhibitors [8,9]. L-Proline was utilized as a platform to construct the indolizidine skeleton, as shown in Scheme 1. (E)-Silyl enol ether 2, obtained from L-proline via a known protocol $[10,11]$, underwent an aza-Claisen rearrangement to produce the corresponding 9-membered lactam 3 in $66 \%$ yield. This transformation was impressive not only because it created a new stereogenic center through a 6-membered transition state, but also because it afforded a cis-azoninone framework simultaneously. The final product $\mathbf{4}$ was afforded after subsequent transformations. Similarly, (Z)-silyl enol ether $\mathbf{5}$ was converted into trans-azoninone $\mathbf{6}$ under microwave-assisted conditions. It is noteworthy that the syn-diol moiety of the azoninone skeleton was created via chiral communication of the L-proline stereocenter during aza-Claisen rearrangement-induced ring expansion. The transition states in both these conversions made it possible for the sole chiral center of amino acid $\mathbf{1}$ to induce additional chirality in cis or trans azoninones $\mathbf{3}$ and $\mathbf{6}$.

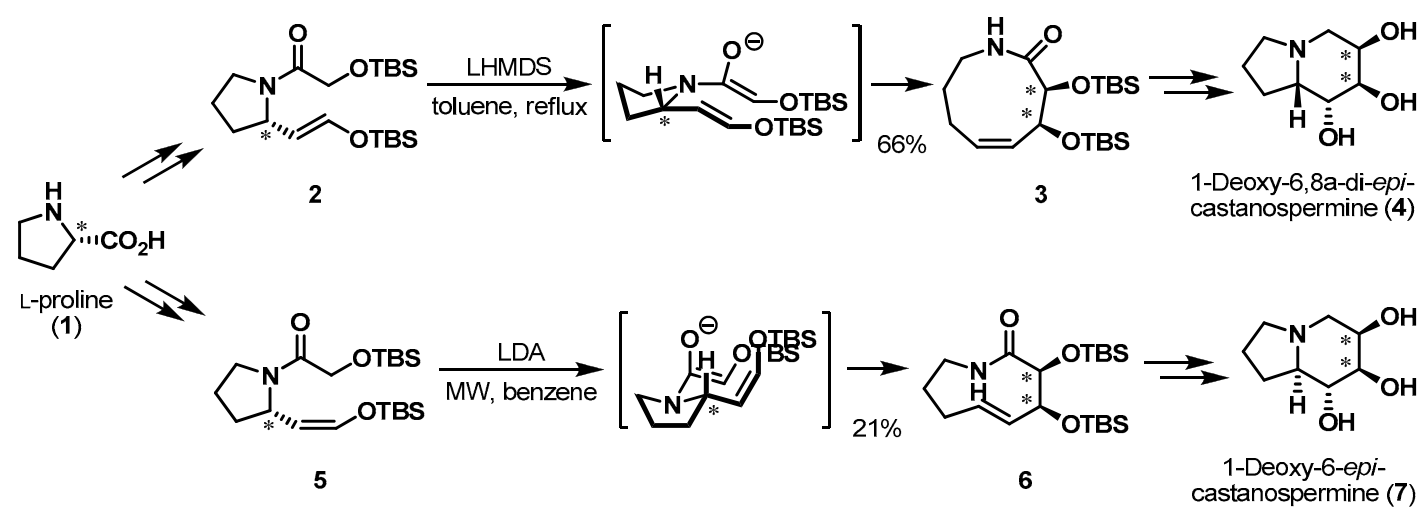

Scheme 1. Total syntheses of castanospermines 4 and 7. 
Another substrate-controlled chiral induction application of L-proline is summarized in Scheme 2. Srihari et al. accomplished the stereoselective total synthesis of alkaloid (-)-allonorsecurinine (10) [12]. To create the stereocenter in the lactone moiety of 10, precursor $\mathbf{8}$ was readily prepared from L-proline in three steps. The Grignard reaction of isopropenyl magnesium bromide with $\alpha$-amidoketone 8 afforded tertiary alcohol 9 in high yield and with excellent facial selectivity, with the pivotal tertiary alcohol moiety in 9 constructed via Si-face addition to the carbonyl group. With key intermediate 9 in hand, subsequent classical reactions, such as Aldol and Horner-Wittig reactions, provided final product 10, a Euphorbiaceae alkaloid.

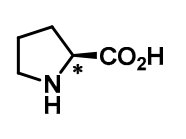

L-proline (1)

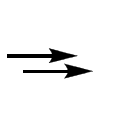<smiles></smiles>

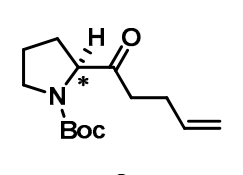

8

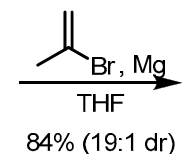

$84 \%(19: 1 \mathrm{dr})$

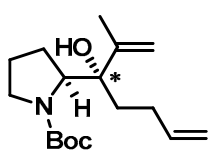

9

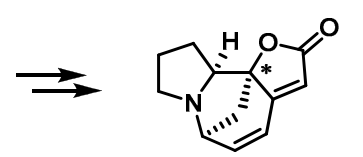

(-)-Allonorsecurinine (10)

Scheme 2. Total synthesis of (-)-allonorsecurinine (10).

Cycloaddition reactions have also been adapted for the proline-derived total synthesis of natural products. Sarpong et al. completed the impressive syntheses of ent-citrinalin B (15) and cyclopiamine B (16) as shown in Scheme 3 [13-15]. The authors utilized the chirality of D-proline for the stereoselective construction of a cis-fused ring system within final products $\mathbf{1 5}$ and $\mathbf{1 6}$. Unsaturated cyanoamide 12 was prepared from D-proline in 55\% yield over seven steps for use as a dienophile in the key face-selective Diels-Alder reaction. When diene $\mathbf{1 3}$ underwent cycloaddition with $\mathbf{1 2}$ in the presence of Lewis acid [16], desired product 14 was obtained in 73\% yield after a basic work-up. As dienophile 12 provided a convex face environment in the bicyclic ring system, diene $\mathbf{1 3}$ approached the $\beta$-face of the unsaturated lactam ring selectively, establishing the two adjacent stereocenters in tricyclic ketone 14 simultaneously. Subsequent steps transformed 14 into ent-citrinalin B (15) and cyclopiamine B (16).
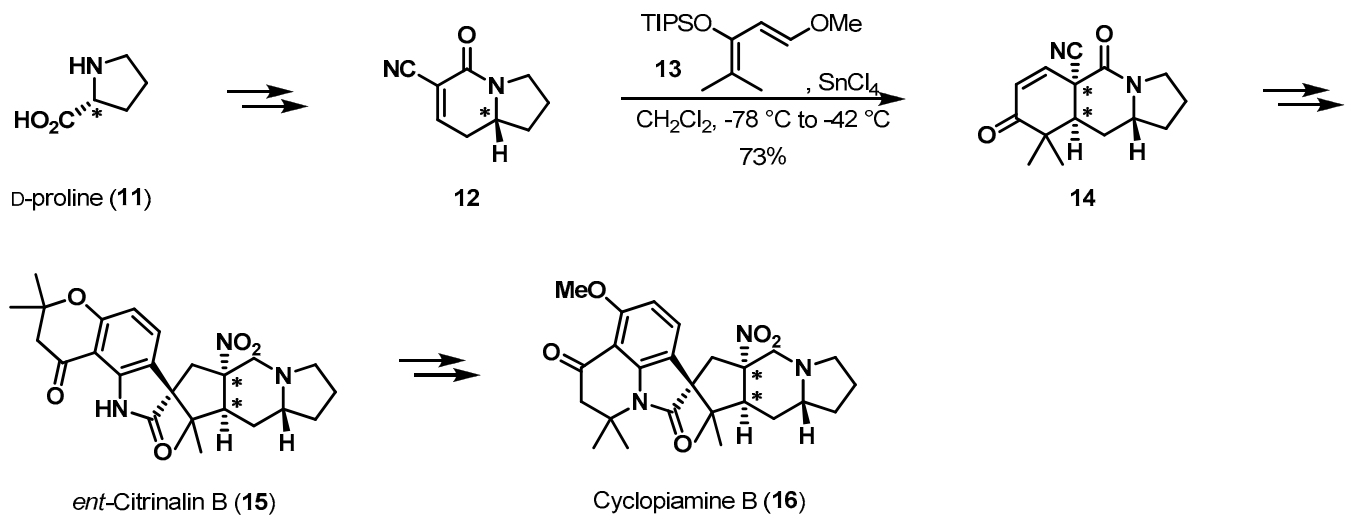

Scheme 3. Total syntheses of ent-citrinalin B (15) and cyclopiamine B (16).

Memory of chirality is a very special case. Recently, Kim et al. reported the first total synthesis of (-)-penibruguieramine A (22), employing a biomimetic approach (Scheme 4) [17,18]. Acid 17 was coupled with L-proline $t$-butyl ester (18) in the presence of DCC, providing amide 19, an intramolecular aldol reaction precursor, in 79\% yield. Exposure of 19 to sodium ethoxide enabled the pyrrolizidine backbone and two additional stereogenic centers of $\mathbf{2 1}$ to be established through memory of chirality and concomitant dynamic kinetic resolution. When amide 19 was treated with a base, its central chirality should have been deleted by deprotonation. However, enolate 20 contained a chiral axis, resulting in memory of chirality and hampering racemization. Impressively, the dynamic kinetic resolution of racemic methine occurred, creating an $\alpha$-chiral center in the amide moiety. From this transformation, bicyclic amide 21 was obtained in 77\% yield, with $10 \%$ of the corresponding elimination product. Following an uneventful reduction procedure, (-)-penibruguieramine A was produced from amide 21 in $86 \%$ yield (two steps). 


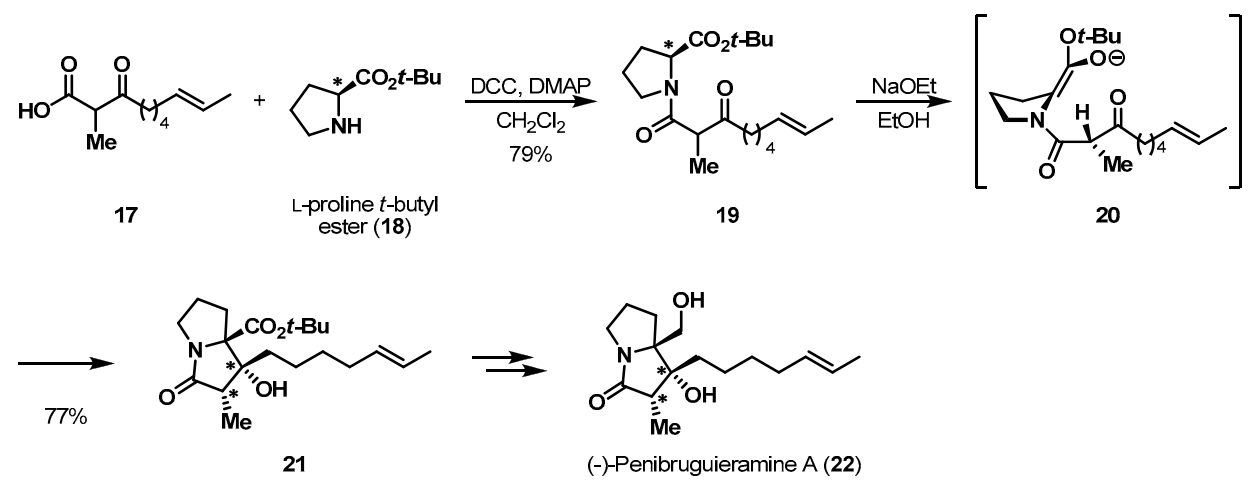

Scheme 4. Total synthesis of penibruguieramine A (22).

\section{Chiral Pool: Tryptophan}

Tryptophan, an aromatic amino acid, has been used as a precursor in the total synthesis of natural products with indole-derived heterocyclic framework. The indole moiety of tryptophan serves as a good template for a copper-catalyzed asymmetric arylation, as depicted in Scheme 5 [19]. Reisman et al. investigated and optimized these reaction conditions. After an extensive survey of bidentate ligands and electrophiles under (CuOTf $)_{2}$ PhMe catalyst, cyclic dipeptide $\mathbf{2 3}$ in the presence of $\mathbf{L} \mathbf{1}$ and $\left[\mathrm{Ph}_{2} \mathrm{I}\right] \mathrm{OTf}$ afforded pyrroloindololine $\mathbf{2 4}$ in high yield and excellent diastereoselectivity, minimizing the undesired C-2 arylated product. Two newly created stereogenic centers were induced by the chirality of tryptophan in a substrate-controlled manner.

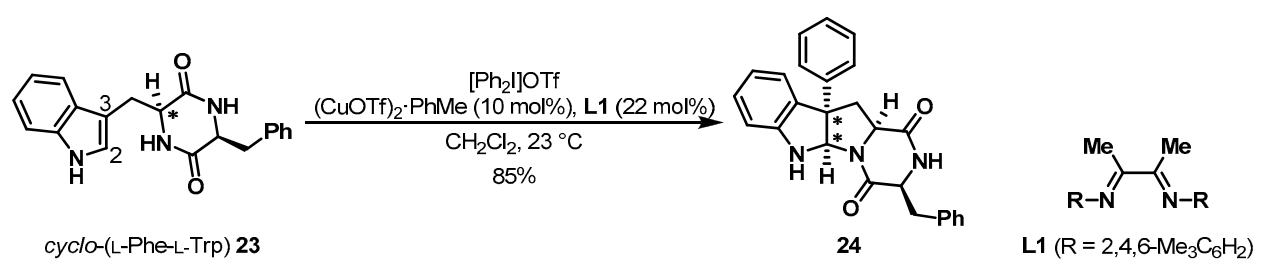

Scheme 5. Cu-catalyzed arylation of cyclo-(Trp-Phe) 23.

This conversion strategy was applied directly to the total synthesis of (+)-naseseazine A (28) and (+)-naseseazine B (30) (Scheme 6) [20]. To construct the tetracyclic framework of 28, cyclic alanine-tryptophan dimer $\mathbf{2 5}$ was selected as a chiral precursor. The pivotal arylation of diketopiperazine $\mathbf{2 5}$ with advanced electrophile $\mathbf{2 6}$ in the presence of $(\mathrm{CuOTf})_{2} \mathrm{PhMe}$ and $\mathbf{L} 2$ provided desired pyrroloindoline $\mathbf{2 7}$ in moderate yield. Final compound $\mathbf{2 8}$ was conveniently constructed from tetracyclic intermediate 27 using a Larock indolization strategy [21,22]. Additionally, another natural product, (+)-naseseazine B, was obtained stereoselectively from cyclic proline-tryptophan precursor $\mathbf{2 9}$, employing a similar synthetic sequence.

Interestingly, applying this methodology to simple carboxamide $\mathbf{3 1}$ afforded pyrroloindololine compound 32, possessing the opposite stereochemistry in the C-2 and C-3 positions. This discrepancy shows that amino acids provide a tremendous opportunity for the diastereoselective synthesis of the pyrroloindololine framework as shown in Scheme 7.

Tryptophan was also utilized as a chiral pool reagent in the total synthesis of prenylated indole alkaloids (-)-brevicompanine B (38) and (+)-aszonalenin (40) (Scheme 8) [23]. Carreira et al. reported a highly diastereoselective and regioselective iridium-catalyzed reverse prenylation reaction. The reaction of readily available L-tryptophan methyl ester 33 with tertiary carbonate 34 in the presence of $\left[\{\operatorname{Ir}(\mathrm{cod}) \mathrm{Cl}\}_{2}\right]$ and phosphoramidite ligand 35 [24] furnished hexahydropyrrolo[2,3- $b$ ]indole (-)-exo-36 in 58\% yield. Initially, the exo/endo ratio of the prenylation was quite low (1.3:1). However, it was improved to $>20: 1$ by extensive optimization of base, ligand, and reaction temperature. Importantly, the installation of two vicinal stereogenic centers was controlled by the chirality of tryptophan. After this successful result, (-)-brevicompanine B (38) [25], a plant growth regulator, 
was finally obtained from iterative amidations in good yield. The total synthesis of another alkaloid, (+)-aszonalenin (40) [26], a substance P inhibitor for the human neurokinin-1 receptor, was efficiently completed from D-tryptophan methyl ester 39 via a similar synthetic procedure.

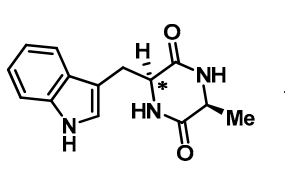

cyclo-(L-Ala-L-Trp) 25

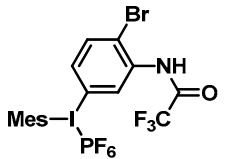

26
$\underset{(\mathrm{CuOTf})_{2} \cdot \mathrm{PhMe}(10 \mathrm{~mol} \%), \mathbf{L 2}(40 \mathrm{~mol} \%)}{\stackrel{\mathrm{CH}_{2} \mathrm{Cl}_{2}, 23^{\circ} \mathrm{C}}{\longrightarrow}}$ $59 \%$

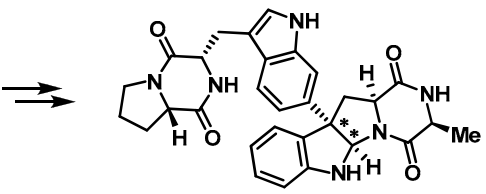

(+)-Naseseazine A (28)
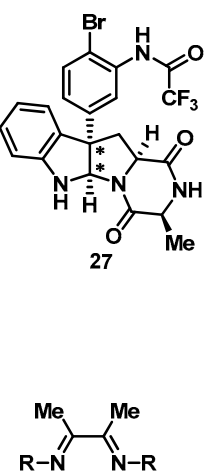

L2 $\left(\mathrm{R}=3,5-(t-\mathrm{Bu})_{2} \mathrm{C}_{6} \mathrm{H}_{3}\right)$

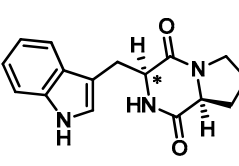

cyclo-(L-Pro-L-Trp) 29

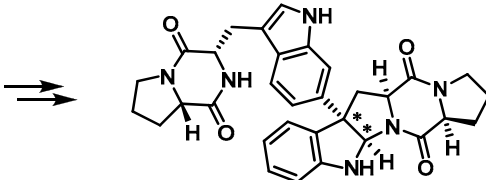

(+)-Naseseazine B (30)

Scheme 6. Total synthesis of (+)-naseseazines A and B.

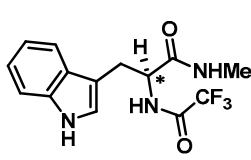

31

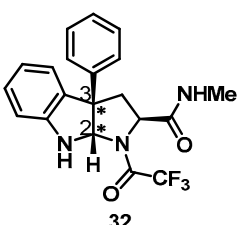

32

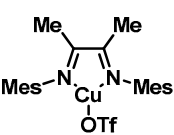

Cu complex

Scheme 7. Diastereoselective cyclization for pyrroloindoline skeleton.

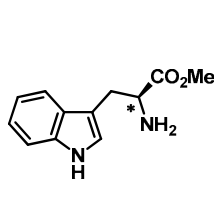

L-tryptophan

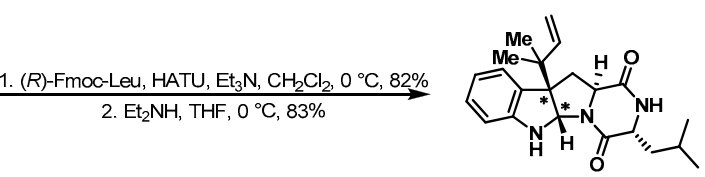

(-)-Brevicompanine B (38)

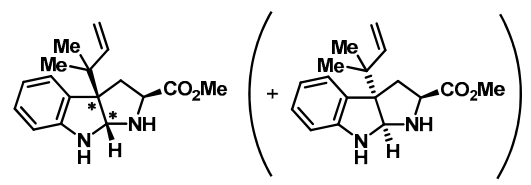

(+)-endo-37

$(-)-e x o-36$

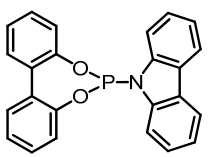

35

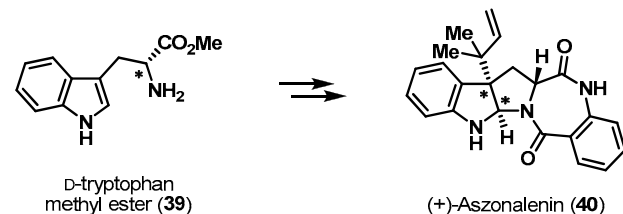

Scheme 8. Total syntheses of (-)-brevicompanine B (38) and (+)-aszonalenin (40). 
A more recent example of tryptophan-templated chiral pool synthesis is illustrated in Scheme 9. Baran et al. accomplished the total syntheses of verruculogen (45) and fumitremorgin A (46), which both contain a unique eight-membered endoperoxide [27-29]. Diastereoselective Pictet-Spengler cyclization of 42, prepared from N-Boc-L-tryptophan methyl ester (41), with TBDPS-protected peroxy-aldehyde 43 gave tricycle 44 . Although the facial selectivity was relatively low (2:1), major diastereomer 44 was effectively exploited to finish the total syntheses. The chirality of tryptophan from the chiral pool was critical for creating the new stereocenter in the indole system. The pivotal methoxy group in precursor 42 was introduced by Ir-catalyzed borylation and Chan-Lam coupling [30].

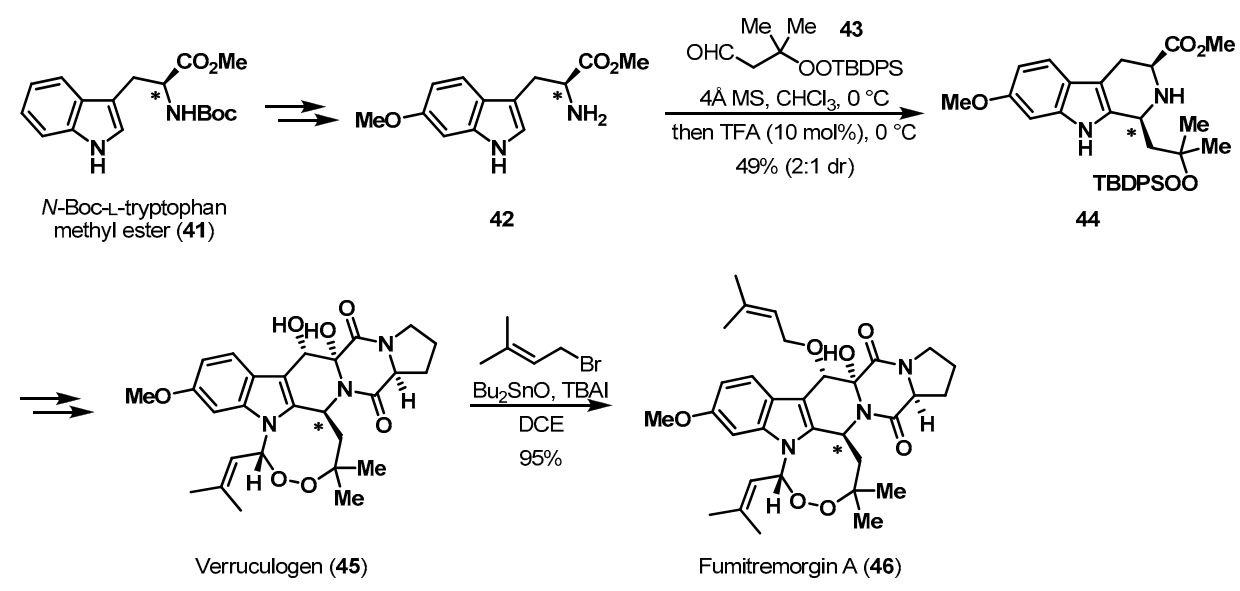

Scheme 9. Total syntheses of verruculogen (45) and fumitremorgin A (46).

\section{Chiral Pool: Tyrosine}

Various natural product syntheses have started from chiral pool reagent tyrosine, which can be transformed into enantiomerically pure intermediates. Tokuyama et al. reported the total synthesis of dimeric alkaloid (-)-acetylaranotin 49 in 2012 (Scheme 10) [31,32]. Alkaloid 49 features a dihydrooxepine backbone synthesized from $\alpha, \beta$-unsaturated ketone 48 by olefin isomerization, Wharton rearrangement, Baeyer-Villiger oxidation, and further steps. The total synthesis commenced with the preparation of enone 48 via oxidative dearomatization of $N$-Cbz-L-tyrosine (47) and subsequent conjugate addition of the transition state amino moiety. This remarkable reaction was previously developed and described by Wipf et al. [33]. After oxidative dearomatization of the phenol moiety in 47 , two transition states, $T_{1}$ and $T_{2}$, for concomitant conjugate addition are possible. $T_{1}$ was more stable, due to having less $\mathrm{A}^{1,3}$-strain ( $\mathrm{H}$ and carbonyl oxygen), resulting in 48 being obtained exclusively as the major diastereomer. This high facial selectivity further demonstrates the superiority of amino acids as chiral inducers.

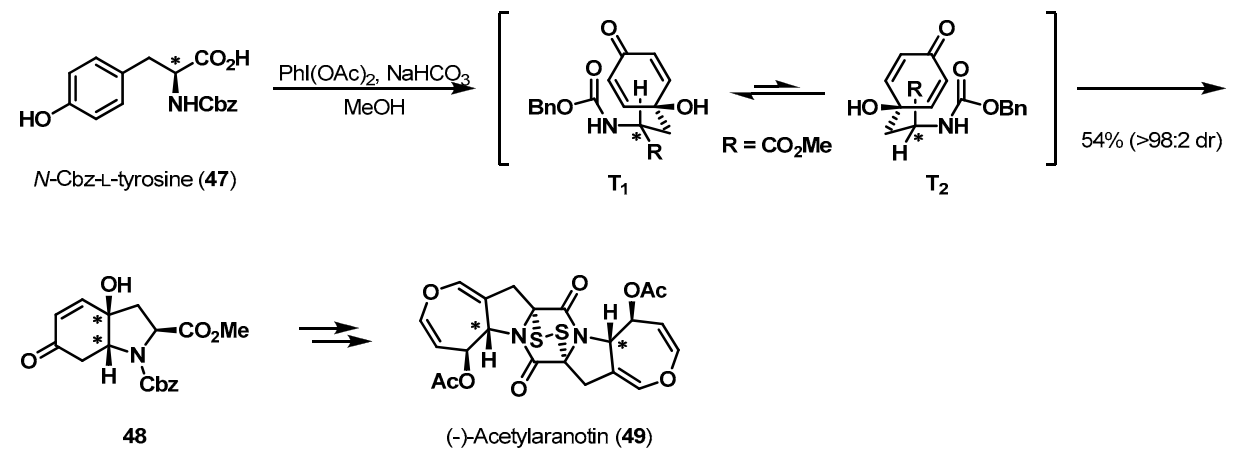

Scheme 10. Total synthesis of (-)-acetylaranotin (49).

Alkene asymmetric dihydroxylation is another example of tyrosine utilized as a chiral template. The stereoselective synthesis of pyrrolidinone alkaloid rigidiusculamide A was completed by 
Krishna et al. (Scheme 11) [34,35]. To incorporate the syn-diol moiety in $\mathbf{5 3}$, they dihydroxylated $\mathbf{5 1}$ using the Upjohn method $\left(\mathrm{OsO}_{4} / \mathrm{NMO}\right)$ [36]. This transformation afforded desired diol $\mathbf{5 2}$ as a single diastereomer in $69 \%$ yield. The chirality of $\gamma$-lactam 52 was thought to be responsible for the enantiomerically pure tyrosine-induced $\alpha$-facial selectivity. Finally, the $O$-benzyl group in $\mathbf{5 2}$ was deprotected to afford the originally proposed structure of rigidiusculamide A. Unfortunately, the experimental data was not identical to that of the authentic natural product [35].

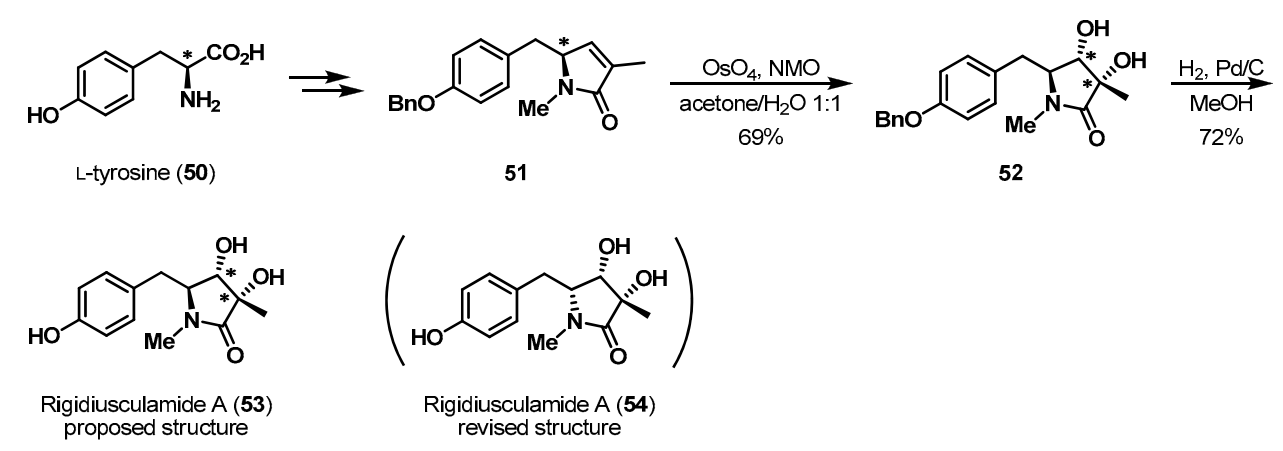

Scheme 11. Total synthesis of rigidiusculamide A (53).

\section{Chiral Pool: Serine}

Serine, containing a hydroxymethyl group, has also been used as the powerful chiral pool reagent in the synthesis of complex target molecules. A particularly impressive example, the enantioselective synthesis of (-)- $\alpha$-kainic acid (60), in which Zhou and Li et al. present a unique $\mathrm{SmI}_{2}$-catalyzed [3 + 2] intramolecular cycloaddition reaction with excellent diastereoselectivity, is summarized in Scheme 12 [37,38]. The key precursor, cyclopropane 56, was synthesized from D-serine methyl ester $\mathrm{HCl}$ (55) using conventional protocols. When cyclopropane $\mathbf{5 6}$ was treated with samarium diiodide, ketyl radical $\mathbf{5 7}$ was initially formed. Rapid cleavage of the cyclopropyl ring and subsequent cycloaddition was observed, which afforded desired bicyclic ketone 59 in good yield. It was hypothesized that ketyl radical 57 spontaneously transformed into enolate radical 58 . This newly created chiral center favored 2,3-trans stereoselectivity over 2,3-cis via facial control from the sole chiral center from the chiral amino acid. With key intermediate 59 in hand, the asymmetric synthesis of kainoid $\mathbf{6 0}$ was accomplished via a high-yielding sequence.

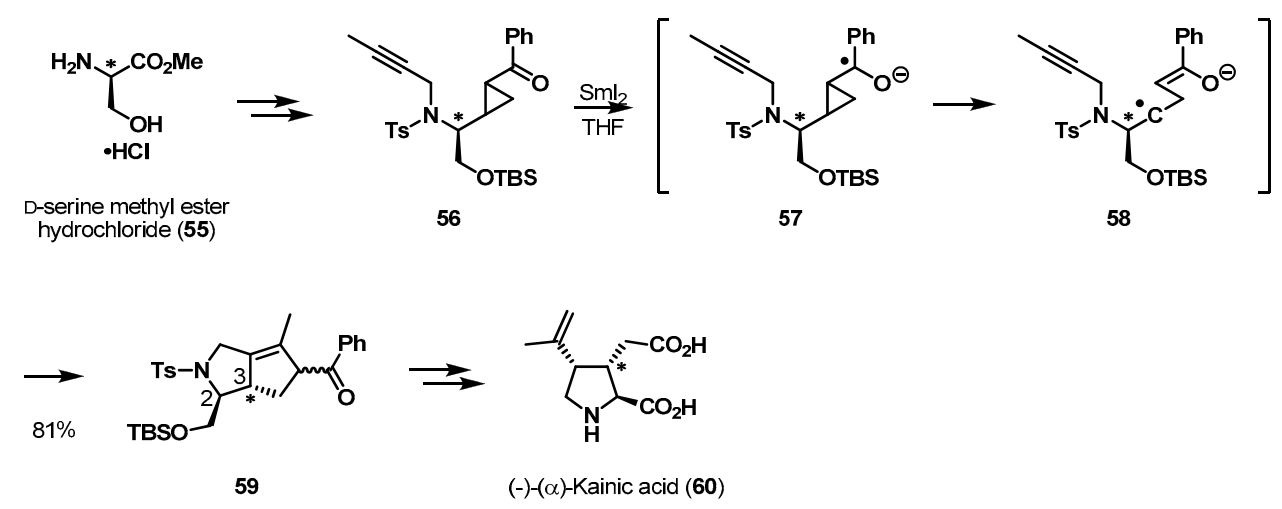

Scheme 12. Total synthesis of (-)- $\alpha$-kainic acid (60).

The synthesis of iso-haouamine B is another example (Scheme 13) $[39,40]$. Structurally, this alkaloid, 64, consists of an indeno-tetrahydropyridine core fused to a highly distinctive 11-membered $p$-cyclophane ring. Trauner et al. investigated a substrate-controlled oxidative phenol coupling to establish the indeno-tetrahydropyridine ring. Coupling precursor enone $\mathbf{6 2}$ was readily prepared from 
N-Boc protected L-serine (61). With desired intermediate 62 prepared, carbonyl activation by triflic anhydride and concomitant 1,4-addition of the electron-rich aromatic ring produced enol ether 63 in moderate yield. During the crucial addition process, the syn-substituted cyclopentane skeleton was constructed without racemization. The new quaternary stereogenic center in $\mathbf{6 3}$ was ultimately derived from the chiral pool stereocenter in 62.

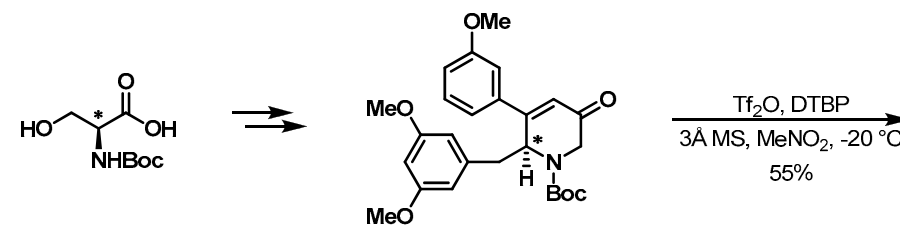

62<smiles>COc1cccc([C@@]23Cc4cc(OC)cc(OC)c4CC2N(C(=O)OCc2ccccc2)CC(O)C3)c1</smiles>

63

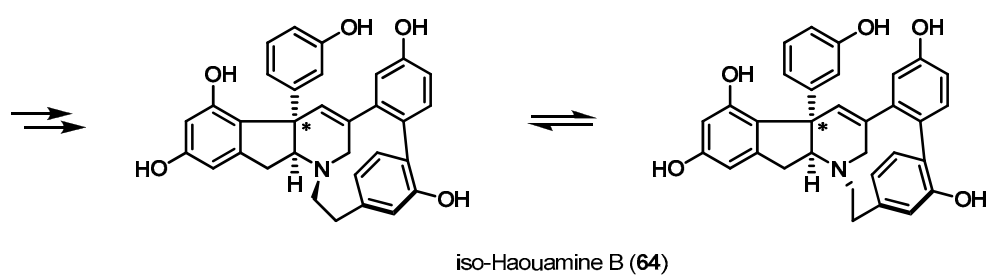

Scheme 13. Total synthesis of iso-haouamine B (64).

More recently, Ciufolini et al. described the total synthesis of (+)-erysotramidine (70) using an L-serine derivative (Scheme 14) [41,42]. Advanced oxazoline 67, prepared from L-serine methyl ester (66) via DCC coupling and Burgess reagent-induced cyclization [43], was converted into enone 68 as a precursor for stereoselective Michael cyclization. Exposure of electronically deficient enone 68 in $\mathrm{CH}_{2} \mathrm{Cl}_{2}$ to $\mathrm{TsOH}$ resulted in the desired tetracyclic core of 69 as a single diastereomer in excellent yield. Although the serine hydroxyl group could approach the two reactive Michael acceptors, the formation of desired product 69 was favored. The high diastereoselectivity was assumed to result from the minimization of unwanted nonbonding interactions between the methyl ester group and acylamido group [44,45]. The pseudoaxial conformation of the methyl ester group resulted from the chirality of serine. After this chiral communication, (+)-erysotramidine (70) was synthesized from key synthetic intermediate 69 using further manipulations.<smiles>COc1cc(CC(=O)O)c(-c2ccc(OC(=O)O)cc2)cc1OC</smiles>

65

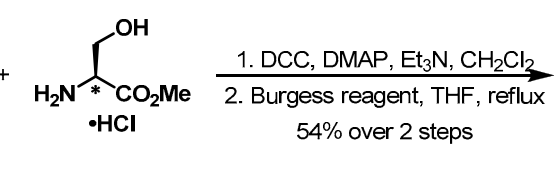

L-serine methyl ester
hydrochloride (66)

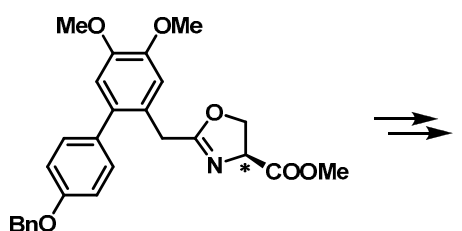

67

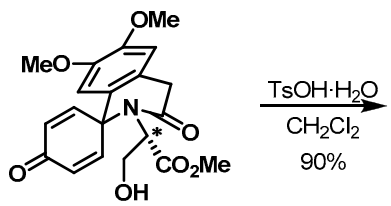

68

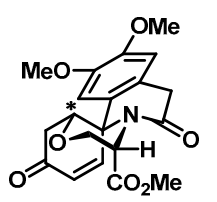

69

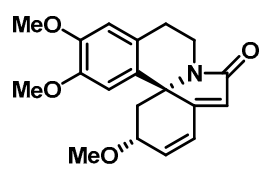

(+)-Erysotramidine (70)

Scheme 14. Total synthesis of (+)-erysotramidine (70).

\section{Chiral Pool: Alanine}

The stereocenter in alanine, a simple chiral pool reagent, has also provided good opportunities for chiral induction. Gouault et al. accomplished the asymmetric total synthesis of dendrobate 
alkaloid (+)-241D (74) and isosolenopsin (76) (Scheme 15) [46-48]. Structurally, these alkaloids consist of cis-2,6-dialkylpiperidine. Vinylogous lactams 72 and 73, which were used as chiral precursors, were readily prepared from $N$-Boc protected D-alanine 71 [49]. The catalytic hydrogenation of Boc-deprotected amine 73 finally gave the target molecule, $(+)-241 \mathrm{D}(74)$, via stereoselective reduction of both the alkene and ketone. In addition, key intermediate 75, which was transformed into enantiopure alkaloid isosolenopsin (76), was obtained by hydrogenation under similar conditions. The newly generated stereogenic centers in $\mathbf{7 4}$ and 75 were affected by the chirality of D-alanine. The total synthesis of isosolenopsin (76) was completed using deoxygenation and Boc-deprotection steps.

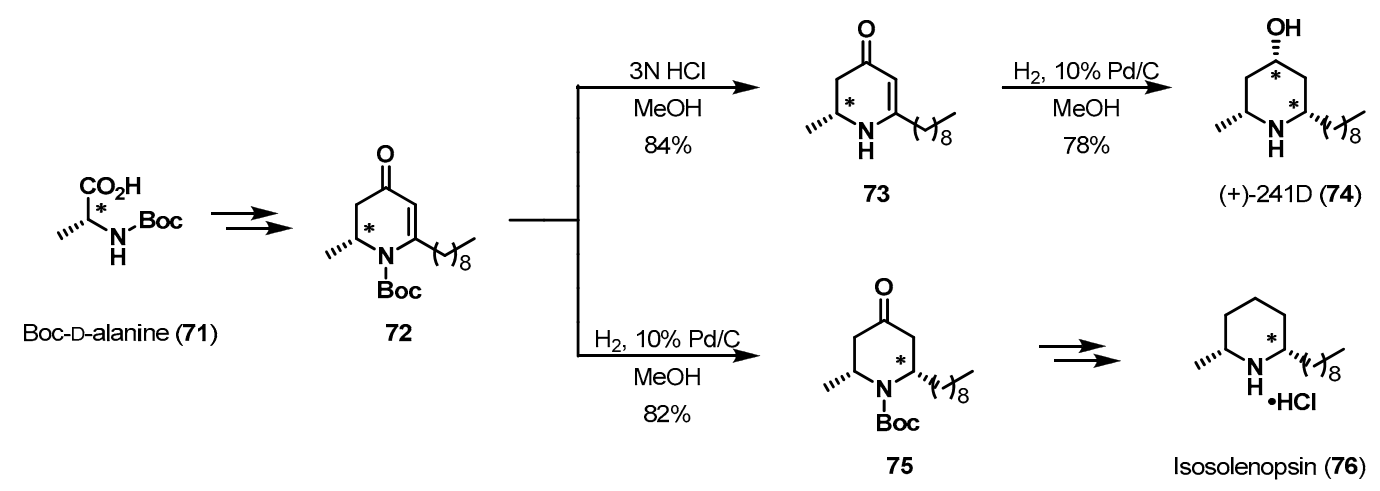

Scheme 15. Total syntheses of (+)-241D (74) and isosolenopsin (76).

\section{Chiral Pool: Threonine}

$\alpha$-Amino acid threonine is a special chiral pool reagent, containing an extra stereocenter. Recently, Seeberger et al. published the total synthesis of protected legionaminic acid 80 from D-threonine as a starting material (Scheme 16) [50,51]. Conventional protection of chiral pool reagent 77, followed by DIBAL-H reduction, provided chiral aldehyde 78 in high yield [52]. With threoninal 78 in hand, treatment with 2-lithiofuran resulted in desired alcohol 79. Although the organometallic addition reaction could produce a diastereomeric mixture, the desired syn-configured alcohol, 79, was obtained with a 5:1 ratio and in $80 \%$ isolated yield. This stereoselectivity was caused by the chirality of threonine amino acid via Cram-chelation control of the nucleophilic addition [53]. The newly generated stereogenic center served as a key stereocenter in C-6 within legionamic acid (81).

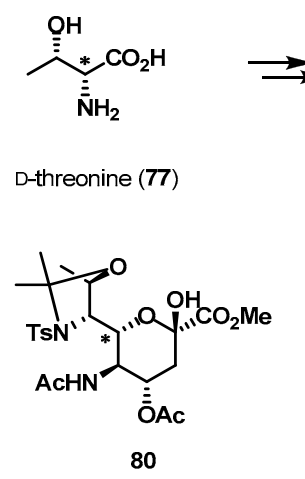

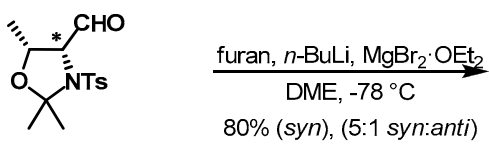

78

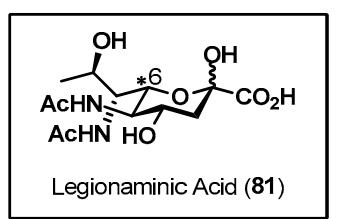

Scheme 16. De novo synthesis of orthogonally protected legionaminic acid $\mathbf{8 0 .}$

\section{Conclusions}

Naturally occurring chiral pool $\alpha$-amino acids provide synthetic chemists with a powerful tool for the incorporation of pivotal stereocenters in optically active natural products. Until now, $\alpha$-amino acids have been exploited for use not only as chiral sources and devices, but also as chiral inducers in 
strategies for the synthesis of complex target molecules. In this review, many applications of $\alpha$-amino acids as chiral inducers in a substrate-controlled manner were specifically discussed. To establish challenging stereocenters in natural product architectures, the chirality of $\alpha$-amino acids was applied to a remarkable variety of reactions, such as rearrangement, cyclization, cycloaddition, nucleophilic addition to carbonyls, and hydrogenation. To conclude, attempts at utilizing $\alpha$-amino acids as chiral inducers for the creation of new stereogenic centers will continue.

Acknowledgments: This research was supported by Basic Science Research Program through the National Research Foundation of Korea (NRF) funded by the Ministry of Science, ICT \& Future Planning (2015R1C1A1A02036681).

Conflicts of Interest: The authors declare no conflict of interest.

\section{Abbreviations}

The following abbreviations are used in this manuscript:

$\begin{array}{ll}\text { Ac } & \text { Acetyl } \\ \text { Ala } & \text { Alanine } \\ \text { BBN } & \text { Borabicyclo[3.3.1]nonane } \\ \text { Bn } & \text { Benzyl } \\ \text { Boc } & \text { t-Butoxycarbonyl } \\ \text { Bu } & \text { Butyl } \\ \text { Cbz } & \text { Benzyloxycarbonyl } \\ \text { cod } & \text { 1,5-Cyclooctadiene } \\ \text { DCE } & \text { 1,1-Dichloroethane } \\ \text { DCC } & \text { N,N'-Dicyclohexylcarbodiimide } \\ \text { DIBAL-H } & \text { Diisobutylaluminum hydride } \\ \text { DMAP } & \text { N,N-4-Dimethylaminopyridine } \\ \text { DME } & \text { 1,2-Dimethoxyethane } \\ \text { DTBP } & \text { 2,6-Di-tert-butylpyridine } \\ \text { Et } & \text { Ethyl } \\ \text { Fmoc } & \text { 9-Fluorenylmethoxycarbonyl } \\ \text { HATU } & \text { O-(7-azabenzotriazol-1-yl)- } N, N, N^{\prime}, N^{\prime} \text {-tetramethyluronium hexafluorophosphate } \\ \text { KHMDS } & \text { Potassium bis(trimethylsilyl)amide } \\ \text { LDA } & \text { Lithium diisopropylamide } \\ \text { Leu } & \text { Leucine } \\ \text { LHMDS } & \text { Lithium bis(trimethylsilyl)amide } \\ \text { Me } & \text { Methyl } \\ \text { Mes } & \text { Mesityl } \\ \text { MS } & \text { Molecular sieves } \\ \text { MW } & \text { Microwave } \\ \text { NMO } & N \text {-Methylmorpholine } N \text {-oxide } \\ \text { Phe } & \text { Phenylalanine } \\ \text { TBAI } & \text { Tetra- } n \text {-butylammonium iodide } \\ \text { TBDPS } & t \text {-Butyldiphenylsilyl } \\ \text { TBS } & t \text {-Butyldimethylsilyl } \\ \text { Tf } & \text { Trifluoromethanesulfonyl } \\ \text { TFA } & \text { Trifluoroacetic acid } \\ \text { THF } & \text { Tetrahydrofuran } \\ \text { TIPS } & \text { Triisopropylsilyl } \\ \text { Trp } & \text { Tryptophan } \\ \text { Ts } & p \text {-toluenesulfonyl } \\ & \\ & \end{array}$

\section{References}

1. Casiraghi, G.; Zanardi, F. Stereoselective Approaches to Bioactive Carbohydrates and Alkaloids-With a Focus on Recent Syntheses Drawing from the Chiral Pool. Chem. Rev. 1995, 95, 1677-1716. [CrossRef]

2. Rouf, A.; Taneja, S.C. Synthesis of Single-enantiomer Bioactive Molecules: A Brief Overview. Chirality 2014, 26, 63-78. [CrossRef] [PubMed]

3. Blaser, H.-U. The Chiral Pool as a Source of Enantioselective Catalysts and Auxiliaries. Chem. Rev. 1992, 92, 835-852. [CrossRef]

4. Nugent, W.A.; RajanBabu, T.V.; Burk, M.J. Beyond Nature's Chiral Pool: Enantioselective Catalysis in Industry. Science 1993, 259, 479-483. [CrossRef] [PubMed] 
5. Goti, A.; Cicchi, S.; Cordero, F.M.; Fedi, V.; Brandi, A. A Straightforward Route to Enantiopure Pyrrolizidines and Indolizidines by Cycloaddition to Pyrroline N-Oxides Derived from the Chiral Pool. Molecules 1999, 4, 1-12. [CrossRef]

6. Haleema, S.; Vavan Sasi, P.; Ibnusaud, I.; Polavarapu, P.L.; Kagan, H.B. Enantiomerically pure compounds related to chiral hydroxy acids derived from renewable resources. RSC Adv. 2012, 2, 9257-9285. [CrossRef]

7. Singh, P.; Samanta, K.; Das, S.K.; Panda, G. Amino acid chirons: a tool for asymmetric synthesis of heterocycles. Org. Biomol. Chem. 2014, 12, 6297-6339. [CrossRef] [PubMed]

8. Yun, H.; Kim, J.; Sim, J.; Lee, S.; Han, Y.T.; Chang, D.-J.; Kim, D.-D.; Suh, Y.-G. Asymmetric Syntheses of 1-Deoxy-6,8a-di-epi-castanospermine and 1-Deoxy-6-epi-castanospermine. J. Org. Chem. 2012, 77, 5389-5393. [CrossRef] [PubMed]

9. Winchester, B.G.; Cenci di Bello, I.; Richardson, A.C.; Nash, R.J.; Fellows, L.E.; Ramsden, N.G.; Fleet, G. The structural basis of the inhibition of human glycosidases by castanospermine analogues. Biochem. J. 1990, 269, 227-231. [CrossRef] [PubMed]

10. Paek, S.-M.; Kim, N.-J.; Shin, D.; Jung, J.-K.; Jung, J.-W.; Chang, D.-J.; Moon, H.; Suh, Y.-G. A Concise Total Synthesis of (+)-Tetrabenazine and (+)- $\alpha$-Dihydrotetrabenazine. Chem. Eur. J. 2010, 16, 4623-4628. [CrossRef] [PubMed]

11. Taniguchi, Y.; Inanaga, J.; Yamaguchi, M. Use of 1,8-Diazabicyclo[5.4.0]undec-7-ene in Preparation of Trimethylsilyl Enol Ethers and Trimethylsilylacetylenes. Bull. Chem. Soc. Jpn. 1981, 54, 3229-3230. [CrossRef]

12. Reddy, A.S.; Srihari, P. A facile approach to the synthesis of securinega alkaloids: stereoselective total synthesis of (-)-allonorsecurinine. Tetrahedron Lett. 2012, 53, 5926-5928. [CrossRef]

13. Mercado-Marin, E.V.; Garcia-Reynaga, P.; Romminger, S.; Pimenta, E.F.; Romney, D.K.; Lodewyk, M.W.; Williams, D.E.; Andersen, R.J.; Miller, S.J.; Tantillo, D.J.; et al. Total synthesis and isolation of citrinalin and cyclopiamine congeners. Nature 2014, 509, 318-324. [CrossRef] [PubMed]

14. Bond, R.F.; Boeyens, J.C.A.; Holzapfel, C.W.; Steyn, P.S. Cyclopiamines A and B, novel oxindole metabolites of Penicillium cyclopium westling. J. Chem. Soc. Perkin Trans. 1 1979, 1751-1761. [CrossRef]

15. Pimenta, E.F.; Vita-Marques, A.M.; Tininis, A.; Seleghim, M.H.R.; Sette, L.D.; Veloso, K.; Ferreira, A.G.; Williams, D.E.; Patrick, B.O.; Dalisay, D.S.; Andersen, R.J.; Berlinck, R.G.S. Use of Experimental Design for the Optimization of the Production of New Secondary Metabolites by Two Penicillium Species. J. Nat. Prod. 2010, 73, 1821-1832. [CrossRef] [PubMed]

16. Kishi, Y.; Nakatsubo, F.; Aratani, M.; Goto, T.; Inoue, S.; Kakoi, H. Synthetic approach towards tetrodotoxin. I. Diels-Alder reaction of $\alpha$-oximinoethylbenzoquinones with butadiene. Tetrahedron Lett. 1970, 11, 5127-5128. [CrossRef]

17. Kim, J.H.; Lee, S.; Kim, S. Biomimetic Total Synthesis of (-)-Penibruguieramine A Using Memory of Chirality and Dynamic Kinetic Resolution. Angew. Chem. Int. Ed. 2015, 54, 10875-10878. [CrossRef] [PubMed]

18. Zhou, Z.-F.; Kurtán, T.; Yang, X.-H.; Mándi, A.; Geng, M.-Y.; Ye, B.-P.; Taglialatela-Scafati, O.; Guo, Y.-W. Penibruguieramine A, a Novel Pyrrolizidine Alkaloid from the Endophytic Fungus Penicillium sp. GD6 Associated with Chinese Mangrove Bruguiera gymnorrhiza. Org. Lett. 2014, 16, 1390-1393. [CrossRef] [PubMed]

19. Kieffer, M.E.; Chuang, K.V.; Reisman, S.E. Copper-Catalyzed Diastereoselective Arylation of Tryptophan Derivatives: Total Synthesis of (+)-Naseseazines A and B. J. Am. Chem. Soc. 2013, 135, 5557-5560. [CrossRef] [PubMed]

20. Raju, R.; Piggott, A.M.; Conte, M.; Aalbersberg, W.G.L.; Feussner, K.; Capon, R.J. Naseseazines A and B: A New Dimeric Diketopiperazine Framework from a Marine-Derived Actinomycete, Streptomyces sp. Org. Lett. 2009, 11, 1390-1393. [CrossRef] [PubMed]

21. Larock, R.C.; Yum, E.K. Synthesis of Indoles via Palladium-Catalyzed Heteroannulation of Internal Alkynes. J. Am. Chem. Soc. 1991, 113, 6690-6692. [CrossRef]

22. Garfunkle, J.; Kimball, F.S.; Trzupek, J.D.; Takizawa, S.; Shimamura, H.; Tomishima, M.; Boger, D.L. Total Synthesis of Chloropeptin II (Complestatin) and Chloropeptin I. J. Am. Chem. Soc. 2009, 131, 16036-16038. [CrossRef] [PubMed]

23. Ruchti, J.; Carreira, E.M. Ir-Catalyzed Reverse Prenylation of 3-Substituted Indoles: Total Synthesis of (+)-Aszonalenin and (-)-Brevicompanine B. J. Am. Chem. Soc. 2014, 136, 16756-16759. [CrossRef] [PubMed]

24. Diebolt, O.; Tricas, H.; Freixa, Z.; van Leeuwen, P.W.N.M. Strong $\pi$-Acceptor Ligands in Rhodium-Catalyzed Hydroformylation of Ethene and 1-Octene: Operando Catalysis. ACS Catal. 2013, 3, 128-137. [CrossRef] 
25. Kusano, M.; Sotoma, G.; Koshino, H.; Uzawa, J.; Chijimatsu, M.; Fujioka, S.; Kawano, T.; Kimura, Y. Brevicompanines A and B: New plant growth regulators produced by the fungus, Penicillium brevicompactum. J. Chem. Soc. Perkin Trans. 1 1998, 1, 2823-2826. [CrossRef]

26. Kimura, Y.; Hamasaki, T.; Nakajima, H.; Isogai, A. Structure of aszonalenin, a new metabolite of aspergillus zonatus. Tetrahedron Lett. 1982, 23, 225-228. [CrossRef]

27. Feng, Y.; Holte, D.; Zoller, J.; Umemiya, S.; Simke, L.R.; Phil, S.B. Total Synthesis of Verruculogen and Fumitremorgin A Enabled by Ligand-Controlled C-H Borylation. J. Am. Chem. Soc. 2015, 137, 10160-10163. [CrossRef] [PubMed]

28. Cole, R.J.; Kirksey, J.W.; Moore, J.H.; Blankenship, B.R.; Diener, U.L.; Davis, N.D. Tremorgenic Toxin from Penicillium verruculosum. Appl. Microbiol. 1972, 24, 248-250. [PubMed]

29. Yamazaki, M.; Suzuki, S.; Miyaki, K. Tremorgenic Toxins from Aspergillus fumigatus FRES. Chem. Pharm. Bull. 1971, 19, 1739-1740. [CrossRef] [PubMed]

30. Shade, R.E.; Hyde, A.M.; Olsen, J.-C.; Merlic, C.A. Copper-Promoted Coupling of Vinyl Boronates and Alcohols: A Mild Synthesis of Allyl Vinyl Ethers. J. Am. Chem. Soc. 2010, 132, 1202-1203. [CrossRef] [PubMed]

31. Fujiwara, H.; Kurogi, T.; Okaya, S.; Okano, K.; Tokuyama, H. Total Synthesis of (-)-Acetylaranotin. Angew. Chem. Int. Ed. 2012, 51, 13062-13065. [CrossRef] [PubMed]

32. Nagarajan, R.; Huckstep, L.L.; Lively, D.H.; DeLong, D.C.; Marsh, M.M.; Neuss, N. Aranotin and Related Metabolites from Avachniofus Aureus I. Determination of Structure. J. Am. Chem. Soc. 1968, 90, 2980-2982. [CrossRef]

33. Wipf, P.; Kim, Y.; Goldstein, D.M. Asymmetric Total Synthesis of the Stemona Alkaloid (-)-Stenine. J. Am. Chem. Soc. 1995, 117, 11106-11112. [CrossRef]

34. Krishna, P.R.; Reddy, B.K. Total Synthesis of a Pyrrolidin-2-one with the Structure Proposed for the Alkaloid Rigidiusculamide A. Helv. Chim. Acta 2013, 96, 1564-1570. [CrossRef]

35. Li, J.; Liu, S.; Niu, S.; Zhuang, W.; Che, Y. Pyrrolidinones from the Ascomycete Fungus Albonectria rigidiuscula. J. Nat. Prod. 2009, 72, 2184-2187. [CrossRef] [PubMed]

36. Vanrheenen, V.; Kelly, R.C.; Cha, D.Y. An improved catalytic $\mathrm{OsO}_{4}$ oxidation of olefin to cis-1,2-glycols using tertiary amine oxides as the oxidant. Tetrahedron Lett. 1976, 17, 1973-1976. [CrossRef]

37. Luo, Z.; Zhou, B.; Li, Y. Total Synthesis of $(-)-(\alpha)$-Kainic Acid via a Diastereoselective Intramolecular [3 + 2] Cycloaddition Reaction of an Aryl Cyclopropyl Ketone with an Alkyne. Org. Lett. 2012, 14, 2540-2543. [CrossRef] [PubMed]

38. Murakami, S.; Takemoto, T.; Shimizu, Z. The effective principle of Digenea simplex Aq. I. Separation of the effective fraction by liquid chromatography. J. Pharm. Soc. Jpn. 1953, 73, 1026-1028.

39. Matveenko, M.; Liang, G.; Lauterwasser, E.M.W.; Zubía, E.; Trauner, D. A Total Synthesis Prompts the Structure Revision of Haouamine B. J. Am. Chem. Soc. 2012, 134, 9291-9295. [CrossRef] [PubMed]

40. Garrido, L.; Zubía, E.; Ortega, M.J.; Salvá, J. Haouamines A and B: A New Class of Alkaloids from the Ascidian Aplidium haouarianum. J. Org. Chem. 2003, 68, 293-299. [CrossRef] [PubMed]

41. Paladino, M.; Zaifman, J.; Ciufolini, M.A. Total Synthesis of (+)-3-Demethoxyerythratidinone and (+)-Erysotramidine via the Oxidative Amidation of a Phenol. Org. Lett. 2015, 17, 3422-3425. [CrossRef] [PubMed]

42. Ito, K.; Furukawa, H.; Haruna, M. Studies on the Erythrina Alkaloids. VII. Alkaloids of Erythrina arborescens ROXB. (2). Structures of New Alkaloids, Erysotramidine, Erytharbine and 11-Hydroxyerysotrine. Yakugaku Zasshi 1973, 93, 1617-1621. [PubMed]

43. Wipf, P.; Miller, C.P. A New Synthesis of Highly Functionalized Oxazoles. J. Org. Chem. 1993, 58, 3604-3606. [CrossRef]

44. Chow, Y.L.; Colòn, C.J.; Tan, J.N.S. A ${ }^{(1,3)}$ interaction and conformational energy of axial-axial 1,3-dimethyl interaction. Can. J. Chem. 1968, 46, 2821-2825. [CrossRef]

45. Lunazzi, L.; Macciantelli, D.; Tassi, D.; Dondoni, A. Conformational studies by dynamic nuclear magnetic resonance. Part 17. Stereodynamic processes in hindered piperidyl-amides and -amidines. J. Chem. Soc. Perkin Trans. 2 1980, 717-723. [CrossRef]

46. Gouault, N.; Le Roch, M.; de Campos Pinto, G.; David, M. Total synthesis of dendrobate alkaloid (+)-241D, isosolenopsin and isosolenopsin A: application of a gold-catalyzed cyclization. Org. Biomol. Chem. 2012, 10, 5541-5546. [CrossRef] [PubMed] 
47. Edwards, M.W.; Daly, J.W.; Myers, C.W. Alkaloids from a Panamanian Poison Frog, Dendrobates speciosus: Identification of Pumiliotoxin-A and Allo-pumiliotoxin Class Alkaloids, 3,5-Disubstituted Indolizidines, 5-Substituted 8-Methylindolizidines, and a 2-Methyl-6-nonyl-4-hydroxypiperidine. J. Nat. Prod. 1988, 51, 1188-1197. [CrossRef] [PubMed]

48. Leclercq, S.; Daloze, D.; Braekman, J.C. Synthesis of the Fire Ant Alkaloids, Solenopsins. A Review. Org. Prep. Proced. Int. 1996, 28, 499-543. [CrossRef]

49. Gouault, N.; le Roch, M.; Cheignon, A.; Uriac, P.; David, M. Enantiospecific Synthesis of Pyridinones as Versatile Intermediates toward Asymmetric Piperidines. Org. Lett. 2011, 13, 4371-4373. [CrossRef] [PubMed]

50. Matthies, S.; Stallforth, P.; Seeberger, P.H. Total Synthesis of Legionaminic Acid as Basis for Serological Studies. J. Am. Chem. Soc. 2015, 137, 2848-2851. [CrossRef] [PubMed]

51. Zunk, M.; Kiefel, M.J. The occurrence and biological significance of the $\alpha$-keto-sugars pseudaminic acid and legionaminic acid within pathogenic bacteria. RSC Adv. 2014, 4, 3413-3421. [CrossRef]

52. Liang, X.; Lee, C.-J.; Chen, X.; Chung, H.S.; Zeng, D.; Raetz, C.R.H.; Li, Y.; Zhou, P.; Toone, E.J. Syntheses, structures and antibiotic activities of LpxC inhibitors based on the diacetylene scaffold. Bioorg. Med. Chem. 2011, 19, 852-860. [CrossRef] [PubMed]

53. Szechner, B.; Achmatowicz, O.; Galdecki, Z.; Fruziński, A. Synthesis and absolute configuration of four diastereoisomeric 1-(2-furyl)-2-aminobutane-1,3-diols. Tetrahedron 1994, 50, 7611-7624. [CrossRef]

(C) 2016 by the authors; licensee MDPI, Basel, Switzerland. This article is an open access article distributed under the terms and conditions of the Creative Commons Attribution (CC-BY) license (http:/ / creativecommons.org/licenses/by/4.0/). 